JGG 2021;69:1-5

doi: $10.36150 / 2499-6564-419$

\title{
Clostridium difficile infection in a Geriatric Care Unit: clinical characteristics and prognosis
}

\author{
Benedetta Govoni ${ }^{1}$, Amedeo Zurloํ, Roberto De Giorgio², \\ Rosario Cultrera ${ }^{3}$, Stefano Volpato ${ }^{1}$ \\ ${ }^{1}$ Geriatrics and Ortogeriatrics Unit, Department of Medical Sciences, University of Ferrara, Italy; \\ ${ }^{2}$ Internal Medicine Unit, Department of Medical Sciences, University of Ferrara, Italy; ${ }^{3}$ Infectious \\ Desease Unit, Department of Medical Sciences, University of Ferrara, Italy
}

Received: July 10, 2020

Accepted: October 5, 2020

\section{Correspondence \\ Stefano Volpato \\ Dipartimento di Scienze Mediche, Università degli Studi di Ferrara, Arcispedale S. Anna di Ferrara, via Aldo Moro 8, Cona 44124, Ferrara, Italy. Tel.: +390532 236658 \\ E-mail: stefano.volpato@unife.it}

\section{Conflict of interest}

The Authors declare no conflict of interest

How to cite this article: Govoni B, Zurlo A, De Giorgio R, et al. Clostridium difficile infection in a Geriatric Care Unit: clinical characteristics and prognosis. Journal of Gerontology and Geriatrics 2021;69:1-5. https://doi.org/10.36150/2499-6564-419

C Copyright by Società Italiana di Gerontologia e Geriatria (SIGG)

\section{(c) (1) $(9)$}

\section{OPEN ACCESS}

This is an open access article distributed in accordance with the CC-BY-NC-ND (Creative Commons Attribution-NonCommercial-NoDerivatives 4.0 International) license. The article can be used by giving appropriate credit and mentioning the license, but only for non-commercial purposes and only in the original version. For further information: https://creativecommons.org/licenses/by-nc-nd/4.0/deed.en
Background \& aims. Clostridium difficile infection (CDI) is a leading cause of nosocomial diarrhoea in elderly people. This study aimed to describe the main clinical features and prognosis at 6 months of patients affected by CDI in a Geriatric Unit.

Methods. Retrospective observational study based on clinical records conducted among elderly patients admitted to a Geriatric Care Unit. Inclusion criteria were: 1) patients discharged with diagnosis of $\mathrm{CDI}$, confirmed by positive fast enzyme immunoassay for detection of $C$. Difficile toxin B on stool sample; 2) availability of Multidimensional Prognostic Index (MPI) score, assessed during the first 48 hours after admission. Secondary analysis was performed to investigate potential risk factors for worse outcomes during hospitalization, and on the incidence of recurrences and survival in a subgroup at 6 months of follow-up.

Results. Thirty-three patients enrolled ( $23 \mathrm{~F}, 10 \mathrm{M})$, mean age 89 years. $\mathrm{CDI}$ was the reason for hospital admission in $39.6 \%$ of cases, while $60.4 \%$ developed the infection during hospitalization. All patients had undergone recent antibiotic treatment and $97 \%$ had recently been hospitalized or were nursing home residents. Ninety percent of subjects had more than two comorbidities and in $85 \%$ of cases, MPI predicted a high risk of mortality. In-hospital mortality was $21 \%$ and, in the subgroup of 16 patients who completed the 6 -month follow-up, $31 \%$ had at least one recurrence and $75 \%$ died.

Conclusions. CDI affects oldest-old and vary frail patients, with high comorbidity and high risk of mortality, and most of them have a poor prognosis, suggesting that CDI might be considered as a frailty marker itself.

Key words: elderly, clostridium difficile, clostridium difficile infection, frailty, multi prognostic index

\section{INTRODUCTION}

Clostridium difficile (C. difficile) is a Gram-positive, anaerobic, spore-forming bacillus, widely distributed in the environment that colonizes from 2.6 to $13 \%$ of healthy adults in different populations ${ }^{1}$. Intestinal colonization is mediated by spores, resistant to heat, dry, acid, chemical agents, including disinfectants and antibiotics and transmitted by faecal-oral route. The organism itself is non-invasive and infection, normally prevented by barrier properties of the faecal microbiota, depends by the virulence of the infecting strain and by the host 
immune response. The pathogenetic strains of $C$. difficile produce large exotoxin proteins, toxin $A(T c d A)$ and toxin $B(T c d B)$, which constitute the principal virulence factors of the microorganism and are used as laboratory markers for diagnosis $^{2}$. Disease caused by $C$. difficile can range from mild diarrhea to severe and complicated manifestations, i.e. fulminant pseudomembranous colitis, toxic megacolon, colon perforation and sepsis ${ }^{3}$.

The incidence of $C$. difficile infection (CDI) in the hospital setting and in other health facilities, such as long-term care, rehabilitation centres or nursing homes, has increased significantly over the past 20 years, becoming the leading and most serious healthcare-associated infectious diarrhoea and related healthcare costs ${ }^{4}$. Most cases occur in elderly patients, with risk factors including prolonged hospitalisation, antibiotic exposure, abnormal gut microbiota and impaired local immunity, often leading to poor prognosis ${ }^{5}$. Also, an increased risk of CDI recurrences may occur even after the end of a properly conducted, specific antibiotic therapy, an event that requires a new hospitalization with high residual disability and mortality. In this study, we investigated the main clinical features of patients affected by CDI in a Geriatric Care Unit in order to describe their characteristics at time of hospital admission and prognosis at 6 months.

\section{MATERIALS AND METHODS}

This is a retrospective observational study based on clinical records collected from elderly patients admitted to the Geriatric Care Unit of St. Anna University Hospital, from 20 March 2018 to 20 March 2019. The Geriatric Care Unit (GCU) has 32 beds, dedicated to the admission of people over 75 years mainly with chronic illnesses with acute exacerbations.

The study enrolled patients with following inclusion criteria: 1) discharge diagnosis of $\mathrm{CDI}$, defined according to the presence of ICD-9-CM code 00845 and confirmed by laboratory tests. Our detection method is based on a rapid membrane enzyme immunoassay for the simultaneous identification of $C$. difficile glutamate dehydrogenase $(G D H)$ antigen and toxins $A$ and $B$ on fresh stool sample (C. DIFF QUICK CHEK ${ }^{\circledR}$, TechLab). If this test resulted positive for $\mathrm{GDH}$, but negative for toxins A/B, GeneXpert ${ }^{\circledR} C$. difficile assay (Cepheid) was used to detect toxigenic $C$. difficile strains; 2) Availability of a complete Multidimensional Prognostic Index (MPI) score ${ }^{6}$, assessed during the first 48 hours after the hospital admission, by trained investigators (medical doctors).

For each patient we collected the following data:

a) Geriatric Care Unite admission date and diagnosis;

b) demographic information, including age, gender and pre-admission family status; c) Comprehensive Geriatric Assessment (GCA) ${ }^{7}$, including domains as comorbidities (Cumulative IIIness Rating Scale), cognitive performance status (Short Portable Mental Status Questionnaire), functional status (Katz and Lawton-Brody index for basic and instrumental activities of daily living), nutritional status (short form of Mini Nutritional Assessment), pressure ulcers risk (Norton and Exton-Smith Scale) and home drug therapy (number and type of drugs);

d) pharmacological therapies set during hospitalization, with particular reference to therapy with proton pump inhibitors and antibiotics;

e) results from fast enzyme immunoassay for detection of $C$. difficile toxin $B$ on stool samples;

f) date of discharge or death.

Information collected through GCA and medical records were used to calculate Multidimensional Prognostic Index (MPI) score. A first descriptive analysis was conducted on the totality of the collected data, while a secondary analysis of the incidence of recurrences and survival was performed in a subgroup of patients who had a 6 months follow-up.

Recurrent $C$. difficile infection $(\mathrm{rCDI})$ was defined as a new symptomatic CDI that re-occurs within 21-30 days after completion of anti-CDI therapy ${ }^{8}$. Outcome data for a 6-month follow-up were collected by identifying subsequent episodes of hospital admission, for each previously enrolled patient, through the hospital information management system and by consulting the related medical record.

The results were reported as frequencies or mean \pm standard deviation whenever appropriated.

\section{RESULTS}

The sample included 35 cases of $C$. difficile infections on 1192 hospitalizations (annual incidence rate 3\%), two of which were re-admissions of previously registered patients. All demographic and clinical characteristics of the study population $(n=33)$ were summarized in Table I. Patients age ranged from 80 to 98 years (mean age 89 years) and 23 were female. CDI was the reason for hospital admission in 13 cases, while the remaining developed it as complication during hospitalization. Four cases were $\mathrm{CDI}$ recurrences already at the baseline. In the two weeks preceding the clinical onset of the disease, all patients had undergone antibiotic treatment and 12 were receiving PPI therapy. Almost the entire sample (30/33) had a recent hospitalization or was nursing home residents. At admission, 28 patients had cognitive impairment (SPMSQ $\geq 3$ errors), 31 had severe functional limitation (defined as $\leq 2$ maintained ADL and IADL) and, among them, 21 subjects were already completely dependent. Thirty patients had 
Table I. Main characteristics of the population studied.

\begin{tabular}{|c|c|}
\hline & N. $=33$ \\
\hline Age, years & $88.8 \pm 4$ \\
\hline Women & $23(69.7 \%)$ \\
\hline \multicolumn{2}{|l|}{ ADL } \\
\hline$\leq 2$ & $31(93.9 \%)$ \\
\hline \multicolumn{2}{|l|}{ IADL } \\
\hline$\leq 2$ & $31(93.9 \%)$ \\
\hline \multicolumn{2}{|l|}{ SPMSQ errors } \\
\hline $\begin{array}{l}\text { 8-10 (severe cognitive impairment) } \\
\text { 3-7 (low-moderate cognitive impairment) } \\
0-2 \text { (no cognitive impairment) }\end{array}$ & $\begin{array}{c}10(30.3 \%) \\
18(54.5 \%) \\
5(5 \%)\end{array}$ \\
\hline \multicolumn{2}{|l|}{ MNA short form } \\
\hline $\begin{array}{l}\text { 12-14 (normal nutritional status) } \\
\text { 8-11 (at risk of malnutrition) } \\
0-7 \text { (malnourished) }\end{array}$ & $\begin{array}{c}4(12.1 \%) \\
9(27.3 \%) \\
20(60.6 \%)\end{array}$ \\
\hline \multicolumn{2}{|l|}{ Exton Smith } \\
\hline $\begin{array}{l}\text { 16-20 (low-risk) } \\
10-15 \text { (moderate-risk) } \\
\text { 5-9 (high-risk) }\end{array}$ & $\begin{array}{c}3(9.1 \%) \\
15(45.5 \%) \\
15(45.5 \%)\end{array}$ \\
\hline \multicolumn{2}{|l|}{ CIRS (n.) } \\
\hline $\begin{array}{l}0 \\
1-2 \\
\geq 3\end{array}$ & $\begin{array}{c}0(0 \%) \\
3(9.1 \%) \\
30(90.9 \%)\end{array}$ \\
\hline \multicolumn{2}{|l|}{ Pharmacotherapy (drugs number) } \\
\hline $\begin{array}{l}0-3 \\
4-6 \\
\geq 7\end{array}$ & $\begin{array}{c}5(15.2 \%) \\
11(33.3 \%) \\
17(51.5 \%)\end{array}$ \\
\hline \multicolumn{2}{|l|}{ Housing situation } \\
\hline $\begin{array}{l}\text { Lives alone } \\
\text { Nursing home residents } \\
\text { Lives with family or caregiver }\end{array}$ & $\begin{array}{c}3(9.1 \%) \\
12(36.4 \%) \\
18(54.5 \%)\end{array}$ \\
\hline MPI & $0.76 \pm 0.15$ \\
\hline $\begin{array}{l}\text { Low-risk }(0-0.33) \\
\text { Mild-risk }(0.34-0.66) \\
\text { Severe-risk (0.67-1) }\end{array}$ & $\begin{array}{c}0(0 \%) \\
5(15.2 \%) \\
28(84.8 \%)\end{array}$ \\
\hline Hospitalized in the previous month & $21(63.6 \%)$ \\
\hline PPI treatment & $12(36.4 \%)$ \\
\hline Concomitant antibiotics & $33(100 \%)$ \\
\hline \multicolumn{2}{|l|}{ CDI time of onset } \\
\hline $\begin{array}{l}\text { Reason for hospitalization } \\
\text { Intra hospitalization complication }\end{array}$ & $\begin{array}{l}13(39.4 \%) \\
20(60.6 \%)\end{array}$ \\
\hline \multicolumn{2}{|l|}{ CDI classification } \\
\hline $\begin{array}{l}\text { Prior CDI Episode } \\
\text { Recurrent CDI }\end{array}$ & $\begin{array}{c}29(87.9 \%) \\
4(12.1 \%)\end{array}$ \\
\hline \multicolumn{2}{|l|}{ Initial antibiotic treatment } \\
\hline $\begin{array}{l}\text { Metronidazole } \\
\text { Vancomycin }\end{array}$ & $\begin{array}{l}11(33.4 \%) \\
22(66.6 \%)\end{array}$ \\
\hline
\end{tabular}

more than two comorbidities (mean CIRS score 5) and in most cases (28/33), MPI was predictive of a high risk of short and long-term mortality (MPI-3) ${ }^{9}$. All affected patients were treated with a specific antibiotic therapy for $C$. difficile enterocolitis: the initial treatment was oral vancomycin in
22/33 and oral metronidazole in the remaining cases. Vancomycin was the treatment of choice in all cases $(n=4)$ of verified recurrence.

Comparing patients who survived at a first CDI episode with those undergoing worse outcomes, such as mortality or re-infection, during hospitalization (Tab. II), to focus on eventually associated risk factors at baseline, none of the variables considered were statistically significant. Regarding prognosis (Fig. 1), in-hospital mortality was in $7 / 33$ patients and, in the subgroup of 16 patients who completed the 6-month follow-up, 5 presented at least one recurrence and 12 died.

\section{DISCUSSION}

This retrospective study, conducted in acutely ill geriatric patients, demonstrated and incident rate of CDI in line with published data ${ }^{10}$ and of relevant impact if related to the number of annual admission in our Geriatric Care Unit. Our data confirmed that $C$. difficile enteritis is a challenging problem in the geriatric setting impacting with tremendous burden on healthcare associated costs, including need for hospitalization, prolonged hospital stay, supplementary therapies, diagnostic investigations ${ }^{11}$. In addition, patients with CDI are at high risk for an extremely poor long-term prognosis with a very high $(75 \%$ I six-month mortality rate, despite a specific antibiotic treatment. Also, based on retrievable data, we showed that CDI treatment management with antibiotic therapy has not yet conformed to the most recent guidelines ${ }^{12,13}$, which exclude metronidazole from the recommended drugs in favour of vancomycin od fidaxomicin even in patients with initial or non severe episodes. We believe that adherence to guidelines/therapeutic protocols is an objective to be pursued in order to improve the short and long-term prognosis of CDI patients.

Regarding the main clinical characteristics of the population studied, the descriptive analysis based on our

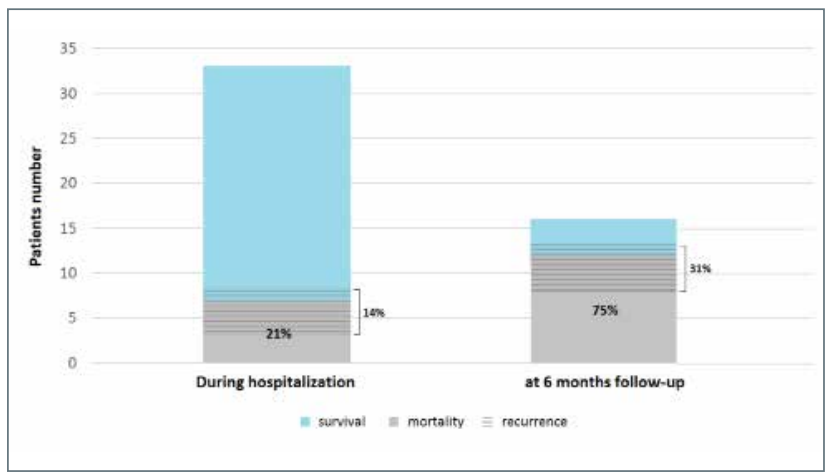

Figure 1. Recurrences and mortality at baseline and at 6 months follow-up. 
Table II. Comparison between patients survived at first CDI episode and those undergoing worse outcomes during hospitalization.

\begin{tabular}{|c|c|c|c|}
\hline & $\begin{array}{l}\text { Survived at first } \\
\text { CDI episode } \\
(\mathrm{n} .=24)\end{array}$ & $\begin{array}{l}\text { Recurrence or death } \\
\text { during hospitalization } \\
\text { (n. = 9) }\end{array}$ & P-value \\
\hline Age, years (average $\pm \mathrm{DS}$ ) & $89( \pm 4)$ & $88( \pm 4)$ & 0.527 \\
\hline Women & $17(71 \%)$ & $6(67 \%)$ & 0.826 \\
\hline ADL & & & 0.454 \\
\hline$\leq 2$ & $23(96 \%)$ & $8(89 \%)$ & \\
\hline IADL & & & 0.454 \\
\hline$\leq 2$ & $23(96 \%)$ & $8(89 \%)$ & \\
\hline SPMSQ errors & & & 0.874 \\
\hline $\begin{array}{l}\text { 8-10 (severe cognitive impairment) } \\
\text { 3-7 (low-moderate cognitive impairment) } \\
\text { 0-2 (no cognitive impairment) }\end{array}$ & $\begin{array}{c}10(42 \%) \\
10(42 \%) \\
4(16 \%)\end{array}$ & $\begin{array}{l}5(56 \%) \\
3(33 \%) \\
1(11 \%)\end{array}$ & \\
\hline MNA short form & & & 0.058 \\
\hline $\begin{array}{l}12-14 \text { (normal nutritional status) } \\
\text { 8-11 (at risk of malnutrition) } \\
0-7 \text { (malnourished) }\end{array}$ & $\begin{array}{c}3(12 \%) \\
9(38 \%) \\
12(50 \%)\end{array}$ & $\begin{array}{c}1(11 \%) \\
0(0 \%) \\
8(89 \%)\end{array}$ & \\
\hline Exton Smith & & & 0.693 \\
\hline \begin{tabular}{|l|}
$16-20$ (low-risk) \\
$10-15$ (moderate-risk) \\
5-9 (high-risk)
\end{tabular} & $\begin{array}{c}2(8 \%) \\
10(42 \%) \\
12(50 \%)\end{array}$ & $\begin{array}{l}1(11 \%) \\
5(56 \%) \\
3(33 \%)\end{array}$ & \\
\hline CIRS (n.) & & & 0.455 \\
\hline $\begin{array}{l}0 \\
1-2 \\
\geq 3\end{array}$ & $\begin{array}{c}0(0 \%) \\
2(8 \%) \\
22(92 \%)\end{array}$ & $\begin{array}{l}0(0 \%) \\
1(11 \%) \\
8(89 \%)\end{array}$ & \\
\hline Pharmacotherapy (drugs number) & & & 0.188 \\
\hline $\begin{array}{l}0-3 \\
4-6 \\
\geq 7\end{array}$ & $\begin{array}{l}3(12 \%) \\
16(67 \%) \\
5(21 \%)\end{array}$ & $\begin{array}{l}2(22 \%) \\
3(33 \%) \\
4(45 \%)\end{array}$ & \\
\hline Housing situation & & & 0.520 \\
\hline $\begin{array}{l}\text { Lives alone } \\
\text { Nursing home residents } \\
\text { Lives with family or caregiver }\end{array}$ & $\begin{array}{c}2(8 \%) \\
10(42 \%) \\
12(50 \%)\end{array}$ & $\begin{array}{l}1(11 \%) \\
2(22 \%) \\
6(67 \%)\end{array}$ & \\
\hline MPI (average \pm DS) & $0.76( \pm 0.17)$ & $0.77(0.14)$ & 0.876 \\
\hline $\begin{array}{l}\text { Low-risk }(0-0.33) \\
\text { Mild-risk }(0.34-0.66) \\
\text { Severe-risk }(0.67-1)\end{array}$ & $\begin{array}{c}0(0 \%) \\
6(25 \%) \\
18(75 \%)\end{array}$ & $\begin{array}{l}0(0 \%) \\
2(22 \%) \\
7(78 \%)\end{array}$ & 1 \\
\hline Hospitalized in the previous month & $15(63 \%)$ & $6(67 \%)$ & 0.833 \\
\hline PPI treatment & $7(30 \%)$ & $5(56 \%)$ & 0.175 \\
\hline Concomitant antibiotics & $24(100 \%)$ & $9(100 \%)$ & \\
\hline CDI time of onset & & & 0.162 \\
\hline $\begin{array}{l}\text { Reason for hospitalization } \\
\text { Intra hospitalization complication }\end{array}$ & $\begin{array}{c}8(33 \%) \\
16(67 \%)\end{array}$ & $\begin{array}{l}5(56 \%) \\
4(44 \%)\end{array}$ & \\
\hline Initial antibiotic treatment & & & 0.102 \\
\hline $\begin{array}{l}\text { Metronidazole } \\
\text { Vancomycin }\end{array}$ & $\begin{array}{l}10(42 \%) \\
14(58 \%)\end{array}$ & $\begin{array}{l}1(11 \%) \\
8(89 \%)\end{array}$ & \\
\hline
\end{tabular}

multidimensional evaluation indicated that the infectious process affected very old people, with a severe clinical status characterized by the presence of multiple comorbidities and a high degree of functional impairment or disability, as proved by a high MPI at the time of hospital admission. The finding of a very high prevalence of infection in patients with previous hospitalization, nursing home residency, or antibiotic treatment confirms the well-known pathogenic mechanisms of CDI transmission and development ${ }^{3}$, and that CDI occurs more often in patients requiring health care assistance.

Compared antibiotics (virtually used by all patients), only $36 \%$ of patients were treated with proton pump inhibitors (PPIs). Recent concern has been raised because of 
the large scale administration of PPI (even beyond what is realistically expected in clinical practice) and their role to evoke changes of the normal profile and biodiversity of the gut microbiota. This mechanism has been postulated to play a role in increasing the harmful power of $C D$ thereby causing enteritis ${ }^{14}$. Although our data cannot establish that PPI can be a risk factor for CDI and other data are necessary to prove such a causal relationship, nonetheless it is worthy to suggest a cautionary approach on the indiscriminate use, likewise antibiotics, of PPIs in hospitalized patients particularly the elderly ones and those with co-morbidities.

Even if none of the variables considered at baseline was statistically associated with a worse outcome during hospitalization, many data are in the expected direction, and might deserve further investigation in larger studies. This study has several limitations, first the small sample size. Secondly, even if the population considered presented a high comorbidity burden and a high risk of short and long-term mortality, the retrospective design of the study did not allow us to explore the contribution of individual diseases and the colonization status of $\boldsymbol{C}$. difficile in order to define the risk of developing CDI and mortality. Thirdly, we only considered patients with CDI infection and therefore the study lacks an appropriate control group in order to investigate clinical correlates of CDI infection. Finally, no phenotypic characterization of CD strains has been assessed in order to correlate this feature with the clinical expression and severity of $\mathrm{CDI}$ and recurrences, compared to new infections by different strains ${ }^{15}$. Nevertheless, our study has also an important element of strength, represented by the fact that data for descriptive analysis, mostly provided by the different MPS's domains, allow us to carry out a multidimensional and complete characterization of patients who developed CDI shifting the focus from an etiological agent's perspective to the pivotal role of the frail acutely ill geriatric host.

In conclusion, the analysis of these data showed that CDI affects elderly-very old and frail patients, with high comorbidity and high risk of mortality. Most of them had a poor prognosis, suggesting that CDI might be considered not only as a negative prognostic factor, but also as a frailty marker itself. We believe that further studies are necessary to explore the relationship between CDI and domains such as multimorbidity, frailty and poly-pharmacotherapy, which are commonly identified among geriatric patients.

\section{References}

1 Ozaki E, Kato H, Kita H, et al. Clostridium difficile colonization in healthy adults: transient colonization and correlation with enterococcal colonization. SJ Med Microbiol 2004;53:167-72. https://doi.org/10.1099/jmm.0.05376-0

2 Jump RLP, Crnich CJ, Mody L, et al. Infectious diseases in older adults of long-term care facilities: update on approach to diagnosis and management. J Am Ger Soc 2018;66:789-803. https://doi.org/10.1111/jgs.15248

3 Czepiel J, Dróżdż M, Pituch $\mathrm{H}$, et al. Clostridium difficile infection: review. Eur J Clin Microbiol Infect Dis 2019;38:121121. https://doi.org/10.1007/s10096-019-03539-6

4 Evelyn Balsells, Ting Shi, Callum Leese, et al. Global burden of Clostridium difficile infections: a systematic review and meta-analysis. J Glob Health 2019;9:010407. https:// doi.org/10.7189/jogh.09.010407

5 Zilio Larentis D, Rosa RG, Pires dos Santos R, et al. Outcomes and risk factors associated with Clostridium difficile diarrhea in hospitalized adult patients. Gastroenterol Res Pract 2015;2015:346341. https://doi.org/10.1155/2015/346341

6 Pilotto A, Ferrucci L, Franceschi M, et al. Development and validation of a multidimensional prognostic index for one-year mortality from comprhensive geriatric assessment in hospitalized older patients. Rejuvenation Res 2008;11:151-61. https://doi.org/10.1089/rej.2007.0569

7 Ellis G, Gardner M, Tsiachristas A, et al. Comprehensive geriatric assessment for older adults admitted to hospital. Cochrane Database Syst Rev 2017;9:CD006211. https:// doi.org/10.1002/14651858

8 Petrosillo N. Tackling the recurrence of Clostridium difficile infection. Med Mal Infect 2018;48:18-22. https://doi. org/10.1016/j.medmal.2017.10.007

9 Volpato S, Bazzano S, Fontana A, et al. MPI-TriVeneto Study Group. Multidimensional Prognostic Index predicts mortality and length of stay during hospitalization in the older patients: a multicenter prospective study. J Gerontol A Biol Sci Med Sci 2015;70:325-31. https://doi. org/10.1093/gerona/glu167

10 Bauer MP, Notermans DW, van Benthem BH, et al.; ECDIS Study Group. Clostridium difficile infection in Europe: a hospital-based survey. Lancet 2011;377:63-73. https:// doi.org/10.1016/S0140-6736(10)61266-4

11 Ghantoji SS, Sail K, Lairson DR, et al. Economic healthcare costs of Clostridium difficile infection: a systematic review. J Hosp Infect 2010;74:309-18. https://doi.org/10.1016/j. jhin.2009.10.016

12 McDonald LC, Gerding DN, Johnson S, et al. Clinical practice guidelines for Clostridium difficile infection in adults and children: 2017 updates by the Infectious Diseases Society of America (IDSA) and Society for Healthcare Epidemiology of America (SHEA). Clin Infect Dis 2018;66:e1-48. https:// doi.org/10.1093/cid/cix1085

13 Petrosillo N, Granata G, Cataldo MA. Novel antimicrobials for the treatment of Clostridium difficile infection. Front Med (Lausanne) 2018;5:96. https://doi.org/10.3389/fmed.2018.00096

14 Trifan A, Stanciu C, Girleanu I, et al. Proton pump inhibitors therapy and risk of Clostridium difficile infection: Systematic review and meta-analysis. World J Gastroenterol 2017;23:6500-15. https://doi.org/10.3748/wjg.v23.i35.6500

15 Durovic A, Widmer AF, Frei R, et al. Distinguishing Clostridium difficile recurrence from reinfection: indipendent validation of current reccomendations. Infect Control Hosp Epidemiol 2017;38:891-6. https://doi.org/10.1017/ice.2017.119 